\title{
SAÚDE BUCALE CUIDADO ODONTOLÓGICO: REPRESENTAÇÕES SOCIAIS DE MÃES USUÁRIAS DE UM SERVIÇO PÚBLICO DE SAÚDE ${ }^{+}$
}

\author{
ORAL HEALTH AND DENTAL CARE: THE SOCIAL REPRESENTATIONS OF \\ MOTHERS WHO ATTEND A PUBLIC HEALTH SERVICE
}

Sidney Marcel Domingues*

Antônio Carlos Duarte de Carvalho**

Paulo Capel Narvai****

Domingues SM, Carvalho ACD de, Narvai PC. Saúde bucal e cuidado odontológico: representações sociais de mães usuárias de um serviço público de saúde . Rev Bras Crescimento Desenvol Hum. 2008; 18(1): 66-78.

\begin{abstract}
Resumo: Objetivo: identificar as representações sociais de mães de crianças da faixa etária de zero a cinco anos de idade do Núcleo de Saúde da Família IV, em Ribeirão Preto - SP, procurando saber o que pensam sobre saúde bucal e tratamento odontológico. Método: trata-se de pesquisa qualitativa, sendo utilizada a entrevista semi-estruturada para a coleta dos dados e a análise de conteúdo. Resultados: constatou-se grande dificuldade das mães em se expressar a respeito do que é, para elas, saúde. Para essas mães a saúde bucal está relacionada com normas de higiene e dietéticas e também com a ida ao dentista, restringindo-se na preocupação com a estética e pouco com a função. Já em relação ao tratamento odontológico, a grande maioria demonstrou apresentar medo, causado pela sua experiência anterior com o tratamento. A assistência particular está associada à pontualidade e ao atendimento da maneira desejada enquanto o tratamento oferecido pelo setor público à demora e à falta de equipamentos e materiais. A humanização no atendimento e competência do profissional emergiram como dois aspectos importantes, e podem estar determinando a decisão de ir ou não ao dentista. Conclusões: A expressão "saúde bucal" foi associada à assistência odontológica. O atendimento pelo setor privado foi referido como o que mais se aproxima do tipo ideal de assistência odontológica.
\end{abstract}

Palavras-chave: Representações; mães; saúde bucal; cuidado odontológico.

\section{INTRODUÇÃO}

A inserção de profissionais de saúde bucal no "Programa de Saúde da Família" (PSF), que vem sendo realizada por alguns municípios, como é o caso de Curitiba, desde antes da criação do programa em 1994, teve importante impulso e se consolidou institucionalmente com a publicação da Portaria n ${ }^{\circ} 1.444$, de 28/12/2000, do ministro da Saúde. Desde então, contudo,

+ $\quad$ Artigo baseado na Dissertação intitulada "Saúde bucal e tratamento odontológico: representações sociais de mães usuárias de um serviço de saúde”, apresentada ao Programa de Pós Graduação em Saúde na Comunidade da Faculdade de Medicina de Ribeirão Preto da Universidade de São Paulo, no ano de 2006; com auxílio da CAPES.

* $\quad$ Mestre em Saúde na Comunidade pela Faculdade de Medicina de Ribeirão Preto da Universidade de São Paulo; e-mail: smdomi@yahoo.com.br

** Docente do Departamento de Medicina Social da Faculdade de Medicina de Ribeirão Preto da Universidade de São Paulo; e-mail: accarval@fmrp.usp.br

**** Docente do Departamento de Práticas em Saúde Pública da Faculdade de Saúde Pública da Universidade de São Paulo; e-mail: pcnarvai@usp.br 
várias dessas iniciativas têm sido questionadas em diferentes graus, ampliando o debate sobre o tema. Entre tais questionamentos argumenta-se sobre o que seria "saúde bucal", as contradições entre o modelo de prática odontológica predominante em nosso meio e sua inadequação à estratégia proposta pelo PSF, as ações mais adequadas a serem desenvolvidas nesta área, o caráter normativo das decisões, e ainda o papel das famílias no processo de planejamento.

Embora a odontologia se ocupe do sistema estomatognático, e comporte especialidades variadas (como entre outras a reabilitação oral, a ortodontia, a endodontia), este deveria ser sempre considerado em suas relações e integração com o corpo físico do ser humano. Freqüentemente, contudo, ocorre o contrário: a prática odontológica tende a reduzir o paciente à cavidade bucal, "esquecendo-se" do restante do corpo físico e de tudo que está no seu entorno, com prejuízos ao conhecimento do paciente como um todo, e implicações decorrentes para o adequado diagnóstico e tratamento.

Ademais, tendo em vista os conhecimentos atuais sobre o processo saúde-doença, sabese que promover saúde e, portanto, saúde bucal, é tão necessário quanto desafiador num país em que uma grande porcentagem da população apresenta edentulismo, dentes cariados, problemas periodontais, ortodônticos e estéticos.

$\mathrm{Na}$ definição da Carta de Ottawa1, "promoção da saúde é o processo de capacitação da comunidade para que ela própria possa participar e controlar ações para a melhoria da sua qualidade de vida e saúde".

Para isso é indispensável conhecer a visão de cada comunidade sobre a saúde e, especificamente em relação à prática odontológica, o que pensa sobre saúde bucal e o cuidado odontológico, pois esses aspectos podem estar influenciando, positiva ou negativamente, decisões importantes com relação à prevenção e tratamento de doenças bucais.

Do ponto de vista epistemológico, a dificuldade de conceituar saúde é reconhecida desde a Grécia antiga. ${ }^{2}$ Há uma carência de estudos sobre esse conceito, parecendo indicar uma dificuldade do paradigma científico dominante nos mais diver- sos campos científicos de abordar a saúde positivamente. Por outro lado, tal pobreza conceitual pode ter sido resultado da influência da indústria farmacêutica e de uma certa cultura da doença, que têm restringido o interesse e os investimentos de pesquisa a um tratamento teórico e empírico da saúde como mera ausência de doença. ${ }^{3}$

Segundo a Lei 8.080, de 19 de setembro de 1990 (BRASIL, 1990) ${ }^{4}$, que dispõe sobre as condições para a promoção, proteção e recuperação da saúde, a organização e o funcionamento dos serviços, "a saúde tem como fatores determinantes e condicionantes, entre outros, a alimentação, a moradia, o saneamento básico, o meio ambiente, o trabalho, a renda, a educação, o transporte, o lazer e o acesso aos bens e serviços essenciais: os níveis de saúde da população expressam a organização social e econômica do país."

Já em Narvai ${ }^{5}$ a "saúde bucal" é conceituada como sendo "um conjunto de condições objetivas (biológicas) e subjetivas (psicológicas) que possibilita ao ser humano exercer funções como mastigação, deglutição, fonação e também, tendo em vista a dimensão estética inerente à região anatômica, exercitar a auto-estima e relacionar-se socialmente sem inibição ou constrangimento."

De acordo com esta concepção, saúde bucal é o resultado da harmonia entre essas condições objetivas e subjetivas, sendo função da prática odontológica realizar, direta ou indiretamente, as ações necessárias à sua produção, tanto no âmbito da sociedade quanto no acompanhamento preventivo-terapêutico realizado pelo dentista. Esse acompanhamento deve ser iniciado o mais precocemente possível, de preferência com as crianças na faixa etária de zero a cinco anos de idade, e envolver toda a equipe de saúde, notadamente médicos pediatras e pessoal de enfermagem que mantêm contato periódico com as crianças e seus pais nessa fase do seu desenvolvimento. Os conhecimentos atuais indicam que é imprescindível que pais e cuidadores sejam orientados para o desenvolvimento de certas ações domésticas, como a realização de uma boa higienização bucal, de modo a acostumar a criança com a manipulação da boca e a sensação de "boca 
limpa", a importância da manutenção da saúde bucal e geral, o irrompimento dos dentes decíduos e as implicações dos problemas nessa primeira dentição para a dentição permanente. ${ }^{6}$

Neste contexto, ganha destaque a figura da mãe que tem importância no interior do ambiente familiar, devido ao fato de ser, segundo Queiroz $^{8}$, a personagem principal da família, com voz decisória, no trato de questões de saúde e doença e de, segundo Alves ${ }^{9}$, ser responsável pelo equilíbrio no binômio saúde-doença. Dessa forma, ela poderia influenciar, positiva ou negativamente, as ações de promoção da saúde bucal, sendo o seu papel decisivo para uma boa ou má educação em saúde bucal da criança e, por extensão, da família como um todo.

Assim, o objetivo deste estudo é de verificar o que pensam as mães de crianças usuárias de um serviço público de saúde sobre saúde, saúde bucal e cuidado odontológico, inseridas no programa de saúde da família.

\section{MÉTODO}

Trata-se de pesquisa qualitativa, com 10 mães de crianças de zero a cinco anos de idade adscritas ao Núcleo de Saúde da Família IV (NSF-IV), vinculado ao Centro de Saúde-Escola "Dr. Joel D. Machado", da Faculdade de Medicina de Ribeirão Preto da Universidade de São Paulo (FMRP-USP), onde o PSF está sendo desenvolvido, em Ribeirão Preto, SP. Foram consideradas participantes da população de estudo as mães (de qualquer idade, classe social, condição física, etnia, profissão, condição marital) que, necessariamente, tivessem um filho na faixa etária de zero a cinco anos. Todas foram convidadas para participar da pesquisa e, quando aceitaram, foram informadas e tiveram suas dúvidas esclarecidas, assinando livremente o respectivo termo de consentimento. O projeto de pesquisa foi aprovado pelo Comitê de Ética em Pesquisa da FMRP/USP sob n ${ }^{\circ}$ 0148/CEP/CSEFMRP/USP. Foram devidamente resguardados o anonimato, o sigilo e a privacidade das mulheres entrevistadas.

Para a coleta de dados, empregou-se a técnica de entrevista semi-estruturada, gravada na residência das mães e norteada por um roteiro específico onde se objetivava obter dados sócio-demográficos para a sua caracterização e suas manifestações sobre alguns temas como: a prática do cuidado, a visão sobre saúde bucal e o significado do tratamento odontológico. Ainda na segunda parte, as mães eram submetidas, primeiramente, ao ruído do instrumento de alta rotação (o popularmente chamado "motorzinho do dentista") e, em seguida, apresentava-se-lhes uma figura contendo um dentista realizando o tratamento odontológico, ambos com o intuito de tentar contribuir na identificação das representações a respeito do cuidado odontológico.

Para a análise dos dados realizou-se análise de conteúdo, um método de tratamento de dados obtidos em textos, compreendida como "um conjunto de técnicas de análise das comunicações, que utiliza procedimentos sistemáticos e objetivos de descrição do conteúdo das mensagens". ${ }^{10}$

Este tipo de análise propõe várias modalidades técnicas, sendo que todas buscam compreender os conteúdos manifestos, ocultos, e suas significações, buscando ultrapassar o olhar imediato das aparências, e estudar o problema a partir da própria expressão dos indivíduos. Neste estudo, dentre as técnicas de análise de conteúdo, foi adotada a análise temática, que consiste em "descobrir os núcleos de sentido que compõem uma comunicação, cuja presença ou freqüência signifiquem alguma coisa para o objetivo analítico visado". ${ }^{11}$

A sistemática para análise dos dados, através da técnica de análise de conteúdo, incluiu a pré-análise, representada pela seleção e organização dos dados; a descrição analítica, na qual os dados foram submetidos a um estudo orientado pelo referencial teórico-metodológico, possibilitando a expressão de concepções relacionadas às categorias já definidas pelo referencial teórico ou que emergiram, e culminou com a interpretação inferencial, em que se elucidaram os aspectos mais latentes, tornando-os mais visíveis. Assim, as categorias de análise que surgiram contemplavam: 1 - quem cuida das crianças; 2 - hábitos e costumes; 3 - representações e crenças em relação à saúde bucal e ao tratamento odontológico; e, 4 acesso ao cuidado odontológico. 


\section{RESULTADOS E DISCUSSÃO}

A análise das entrevistas das 10 mães permitiu identificar suas representações a respeito da saúde bucal e do cuidado odontológico que, para uma melhor apresentação dos resultados, foram subdivididas em três partes que, advindas das questões das entrevistas, expressam suas percepções: 1) a prática do cuidado; 2) saúde bucal na visão das mães; e, 3) o significado do cuidado odontológico. No entanto, antes de apresentar essas representações, faz-se necessária uma caracterização dessas mães e uma breve menção do meio onde vivem para que, assim, contextualizem-se as falas apresentadas nas três partes, de modo a que adquiram sentido e significado plenos.

\section{Caracterização das mães e o meio onde vivem}

A mãe do grupo entrevistado foi caracterizada como uma mulher com cerca de 30,7 anos; parda; com primeiro grau incompleto; residente na favela; convivente; com renda familiar média de 513,5 reais; com cerca de 3,1 filhos. Das que trabalham fora de casa, a grande maioria está no mercado informal, como diarista. As que trabalham em casa são, de forma geral, as responsáveis pelos cuidados com a saúde da família e, especificamente, pelo cuidado em saúde bucal.

\section{A prática do cuidado}

A prática do cuidado é realizada predominantemente pelo sexo feminino, segundo Kars$\mathrm{ch}^{12}$ e Morais ${ }^{13}$. Dias et al. ${ }^{14}$ também constataram que a grande maioria dos cuidadores é do sexo feminino, confirmando que, em geral, as mulheres assumem o cuidar. Este papel, muitas vezes, é visto como natural. Ele está inscrito socialmente no papel de mãe e, culturalmente, as mulheres o assumem como mais um papel pertinente à esfera doméstica.

A manutenção da saúde bucal é um desses papéis. As mães são, significativamente, cobradas em relação a essa obrigação social, sendo apontadas como responsáveis pelas condições de saúde bucal dos seus filhos. ${ }^{15,16}$
As mulheres entrevistadas nesta pesquisa assumem, plenamente, a tarefa de responsáveis pela saúde bucal de seus filhos:

"Ah! Pra mim é... Eu me sinto bem de saber que meu filho pode, tem esse direito, né, de cuidar de, é, todo direito ele tem e esse que é o dentista. Eu me sinto bem. (Em levá-lo ao dentista) Ah! Eu penso que existe e vou fazer isso, né, que tenho que ajudar ele por ele ser pequeno, né, e mesmo depois de grande eu penso que eu tenho que levar porque é importante pra ele, né, é saúde pra ele, então eu tenho que... é minha obrigação de mãe fazer isso, né, de levar ele" (ESA, 25 anos).

Segundo Milgrom ${ }^{17}$ os hábitos adquiridos pela criança estão relacionados com os hábitos da mãe, e o conhecimento e o nível de saúde da mãe podem influenciar no comportamento em relação à sua saúde e a do próprio filho.

Para Ferreira e Gaiva ${ }^{18}$ a "educação odontológica" da mãe é fator determinante para a saúde bucal da futura criança, sendo que a família serve como modelo, auxiliando a criança a cuidar dos seus dentes. Os pais transmitem aos filhos suas fantasias, seus conhecimentos, suas experiências, moldando-os de acordo com suas condições psíquicas e com o grau de maturidade em que se encontram. A influência dos antecessores dos pais explica boa parte do que se passa na relação familiar. Especificamente em relação ao cuidado em saúde bucal, por mais que os filhos participem de programas preventivos nas escolas ou que outra pessoa cuide dessas crianças, quem tem a possibilidade de estar mais próximo e cuidar é a mãe.

Neste estudo verificou-se que, para a grande maioria das entrevistadas, foram suas respectivas mães que as ensinaram a cuidar da boca, sendo que metade delas mencionou exclusivamente a mãe e a outra metade mencionou, além da mãe, outras pessoas como o pai, o médico, o dentista ou uma instituição como a escola.

"Ensinou. Assim, quando eu era criança que (sic) ensinou foi sempre minha mãe a escovar três vezes ao dia, é...passar fio dental, essas coisas, né" (CRS, 48 anos). 
"Ah! Sim. Meu pai, minha mãe, direto. (risos) É. Depois, às vezes, na escola a gente, né, e mais era em casa que... ia pra escola tinha que escovar, levantava, sabe... aquela coisa " (MCM, 35 anos).

Apenas duas entrevistadas mencionaram que ninguém as ensinara a cuidar da sua boca.

Assim, percebe-se que a mãe apresenta um papel extremamente importante no cuidado com a saúde bucal, pois é ela que promoverá, na grande maioria das vezes, os primeiros ensinamentos. Isto é confirmado pela bibliografia que aborda o tema quando se afirma que para que a criança sinta-se motivada a realizar sua higiene bucal, é de fundamental importância a atitude dos pais para incentivar o hábito rotineiramente. Esta prática deve ser realizada no âmbito familiar ainda no período gestacional, através de métodos educativos, reforçando as atitudes positivas em relação à saúde bucal. ${ }^{19}$

Identifica-se nesta pesquisa que, aqueles que ensinaram essas mães a cuidar de sua boca, mencionavam, predominantemente, o cuidado com a prevenção, ou seja, a realização de uma boa e correta escovação dental, o uso do fio dental, a realização de uma boa higiene bucal. Algumas mães mencionaram a ida ao dentista e apenas uma referiu o cuidado com a alimentação.

"Ah! Falava que eu tinha que escovar, ir no dentista, é... usar fio dental, essas coi$s a$ " (FCMC, 20 anos).

"Que não podia comer muito doce, que tinha que escovar o dente desse jeito, três vezes, que passa o fio dental, essas coisa" (ARL, 20 anos).

\section{Saúde bucal na visão das mães}

$\mathrm{O}$ resultado desse estudo evidencia o quanto ainda é difícil, para os sujeitos entrevistados, conceituar "saúde": "Bom, né. Acho bom. Eu não sei te explicar não. Ter saúde..." (EALS, 36 anos).

Um dos aspectos que aparecem intimamente ligados à idéia de saúde é a questão da ausência de doença, mencionada por metade das entrevistadas: "Coisa boa. Ah! Não ser doente, ser uma pessoa saudável" (ARL, 20 anos).

Percebe-se que a noção de saúde como "ausência de doença" é recorrente também nesse grupo de mães. Tal característica expressa o predomínio da postura médica neste contexto. Segundo esta visão, em que a doença corresponde a um mau funcionamento dos mecanismos biológicos, o papel do médico (e do cirurgião-dentista - CD) consistiria em intervir física ou quimicamente para consertar esse "defeito de funcionamento da máquina". ${ }^{20}$ É o que se constata na fala de algumas das entrevistadas: "Ter saúde é uma pessoa que não tem, assim, algum problema, né, diabete, pressão alta, colesterol, essas coisa" (CRS, 48 anos).

Porém, outros conhecimentos e pensamentos são concomitantes no contexto, resultantes provavelmente de mudanças culturais. Exemplo disto é o fato de algumas mencionarem a ida ao médico, o cuidado com a alimentação, a prática da higiene, o estar bem, cuidar da casa, ter disposição para fazer as coisas, não ter problemas, ser feliz e ter liberdade de ir e vir, como condições associadas à idéia de saúde.

“Ai! É o médico, ter boa alimentação, também, é... higiênico dos dente, ter higiênico. Ai!! Um monte de coisa. Cuida da casa também, faz parte da saúde, né?, porque se você habitar numa sujeira, olha, você vai ficar doente, né?" (ALSS, 24 anos).

"Então, eu acho, pra mim, que saúde é tudo, você ter liberdade, você ter... eu acho que, pra mim, a saúde não é só não ter uma doença, entendeu? Pra mim saúde é ser feliz, você ter liberdade pra ir onde você quer, entendeu? Pra mim saúde é tudo" (ESA, 25 anos).

Verifica-se que a percepção das mães em relação à saúde vai além da preocupação consigo mesmas, ao mencionarem pessoas, lugares ou situações que remetem à família.

Os relatos dessas mães (pertencentes a uma população de baixa renda) sobre saúde e os meios de verificar e garantir a saúde da sua família refletem, sobretudo, sua vivência do papel 
de zelar pela saúde daqueles que estão sob sua responsabilidade em casa.

“Ah! É a coisa mais importante, né, tanto pra mim quanto pra ele, porque quando tá, assim, doentinho, eu fico, assim, detonada. Eu não consigo nem trabalhar, porque a preocupação é muita, ne" (MCM, 35 anos).

De forma geral, quando questionadas sobre suas concepções sobre saúde, apesar de terem citado o cuidado com a alimentação e a prática da higiene, poucas mencionaram a higiene dental e nenhuma mencionou a ida ao dentista. Percebe-se assim que, aparentemente, ações de saúde bucal, domésticas ou de assistência à saúde, não emergem espontaneamente como associadas com saúde.

$\mathrm{O}$ discurso dominante entre as entrevistadas revelou que os significados de "saúde bucal" e do "cuidado odontológico" estão relacionados com a escovação (três vezes ao dia), a ingestão de alimentos, a utilização do fio dental, a ausência de cárie, a ausência de mau hálito e a ida ao dentista (a grande maioria não especificou com que frequiência). Assim, o adoecimento bucal, é associado às normas de higiene e dietéticas. Ou seja, para essas mães, saúde bucal não é considerada um estado, mas a atividade de cuidar do corpo. ${ }^{21}$

"Ai! Escovar, todos os dias, toda vez que comer. Também ir no dentista, né, vê se tá tudo bem. Ai, porque dor de dente é horrível. Porque eu senti muita dor de dente. Eu, a partir que eu comecei a sentir dor de dente que eu fui, que eu comecei a ir no dentista" (ALSS, 24 anos).

A despeito de se reconhecer a aceitação universal da necessidade de se cuidar do corpo, cabe assinalar a ideologia subjacente: na medida em que as normas de higiene são prescritas para toda a sociedade, a concepção que predomina é a de que o indivíduo adoece por culpa ou descuido de si próprio. Por consequiência, predomina entre as autoridades da área de saúde e na população, a noção de que o grande responsável pelo adoecimento bucal é o próprio indivíduo. ${ }^{15}$

Essas representações de saúde bucal, como sendo algo fundamentalmente endógeno e de responsabilidade individual, pressupõem a existência de uma sociedade equilibrada e passível de controle pela vontade individual. ${ }^{11}$ No entanto, a nossa estrutura social, longe de ser igualitária, impossibilita, muitas vezes, que as escolhas saudáveis sejam as mais fáceis de serem feitas. ${ }^{22}$

Têm-se, então, uma situação dilemática: de um lado, o trabalho de cuidar, atividade inerente ao ser humano; e, de outro, as dificuldades impostas pela sociedade para a realização de tais atividades.

Nesse contexto, o que deveria ser a prática odontológica? O que deveriam fazer cirurgiões-dentistas e outros membros da equipe de saúde bucal? Segundo as mães ouvidas nesta pesquisa, caberia a esses profissionais o papel de realizar o tratamento dito curativo e/ou fazer a limpeza dos dentes e da boca.

"Eu acho que a função é tratar dos dente, né, olhar, se precisa cuidar ou rancar (sic) ou fazer uma limpeza, né, eu acho que é isso, a função dele" (CRS, 48 anos).

"A função dele é limpar direito o dente, né, e ensinar como escovar também, né, pra gente" (JJO, 27 anos).

"Às vezes, é... assim, em dar tratamento e acho que a psicologia do dentista também pra ele tratar da... do... porque a maioria acho que tem medo, né, (risos) acho que a maioria tem é bastante medo" (MCM, 35 anos).

Todas as entrevistadas mencionaram também que o dentista deveria cuidar de sua própria saúde bucal e que, se fossem ao consultório odontológico e percebessem um descuido do próprio dentista em relação à sua saúde bucal, não gostariam e não voltariam lá. Acreditam que "se ele não cuida dos dele (dentes) vai cuidar do da gente?" (ESA, 25 anos).

Sobre o edentulismo parcial ou total, a maioria das entrevistadas mencionou que a falta dos dentes anteriores é pior do que a falta dos dentes posteriores. 
"Ave Maria! Ai, até agorei já. Porque sim, né, tirar meus dente da frente. Ah!! Os do fundo ainda lá vai, né, tirar. Eu quero tirar dois. Os do fundo não tem problema, os da frente tem" (FCMC, 20 anos).

Percebe-se que a preocupação maior é com a estética, embora se reconheça que a falta de ambos os grupos (anteriores e posteriores) seria muito ruim e feio.

"Nossa!!! Olha!! Eu acho que eu seria...meio incomodada, né, por não ter os dente da frente. Eu acho que você olha, assim, não sei te falar porque, né, mas eu acho que pra mim seria difícil eu aceitar sem dente da frente. (risos) Os do fundo também, porque é...ai...você olha assim você não, né, ai...eu acho todos, né, todos seriam muito feio. Todos são importantes" (MCM, 35 anos).

\section{O significado do tratamento odontológico}

É amplamente reconhecida a importância dos primeiros ensinamentos na infância, pois podem ser apreendidos e permanecer, sendo cruciais no decorrer da vida também com relação à prática odontológica: "Ich! Eu era pequenininha, uns 5 ou 6 anos. Bem pequena. Foi quando eu já entendia, né, as coisas. Minha mãe sempre falava" (ESA, 25 anos).

Segundo as mães, a grande maioria recebeu informações de caráter positivo em relação ao dentista, sendo que apenas uma referiu ter recebido informações de caráter positivo e negativo.

"Eu ouvi que dentista era muito importante, né, pra gente, ahn!, pra depois mais tarde a gente não sofrer, né, porque dor de dente é terrivel, né? (risos) Terrivel" (ESA, 25 anos).

"Ah! Bom, na minha época quando eu era adolescente e eu ia no dentista eu corria, eu tinha medo, porque falavam que quando ia arrancar os dente puxava até o olho saia pra fora. Mas depois acostumei. Ah! Já ouvi muita coisa boa, né, de dentista. Ahn, assim, por exemplo, tem amigas minhas que vão no dentista falam que é bom, que faz limpeza, que cuida do dente, né, costura, se precisar, assim, às vezes ranca, essas coisas que eu já ouvi falar" (CRS, 48 anos).

As primeiras experiências com a prática odontológica são muito significativas, combinando-se com os ensinamentos obtidos antes, na família, para a produção de uma imagem da odontologia e dos trabalhadores da área. É nessa fase da experiência, ao se submeter às ações clínicas, que há um choque das informações transmitidas culturalmente, com a vivência pessoal, e as informações proporcionadas pelo profissional especializado no momento do atendimento.

Neste estudo verificou-se que a grande maioria das entrevistadas apresentou medo e dor na primeira vez em que foi ao dentista: "Ai!! Tive muito medo (risos). Porque eu nunca tinha ido, né, e fui extrair um dente, aí fiquei com medo" (JJO, 27 anos).

Algumas disseram que o primeiro momento foi bom e uma mencionou que nunca fora ao dentista. É imprescindível que o profissional tenha consciência de que esse primeiro momento é muito importante e que pode levar a decisões e comportamentos para uma vida inteira, conforme assinalaram Milgron et al. ${ }^{23}$, para quem o primeiro contato com o dentista é muito importante, podendo ser um fator determinante de ansiedade em relação ao tratamento odontológico.

As consequiências do primeiro contato com o dentista poderiam, por exemplo, levar uma pessoa a nunca mais querer procurá-lo. A fuga do tratamento odontológico pode ser, dessa forma, resultado de experiências aversivas e dolorosas na infância. ${ }^{24}$

O medo surge nos indivíduos de duas formas, distintas e conjugadas: através de suas próprias experiências, ou através das experiências e expectativas dos outros, veiculadas pela mídia e reproduzidas pelo senso comum. Ou seja, os indivíduos vivenciam o medo ou o assimilam, sendo que as situações odontológicas anteriormente vividas pelos pacientes influenciam a sua postura atual frente ao profissional. Os relatos das entrevistadas mostram mudanças de comportamento de acordo com as experiências passadas. Constata-se que as experiências com- 
plicadas, más ou desagradáveis, induzem o paciente ao medo. ${ }^{25}$

"O que eu lembro dessa primeira vez? Que foi muito doloroso (risos). Pra quem nunca conhecia, nunca tinha ido, né, é meio assustador. Tenho medo até hoje. Até hoje tenho. Tenho pavor de dentista (risos)" (CCC, 32 anos).

Já as experiências boas parecem atenuar, de algum modo, o impacto das experiências ruins 25

"Uhm! Faz muito tempo. Ah! A dentista falou pra mim que era pra mim escovar os dente na hora de comer, de jantar, de almoçar. Escovava os dente bem escovado que é pra não ficar comida no dente, né, pra não criar aquele bichinho. Aí... foi isso que ela falou pra mim, que tava bem escovado. Foi bom, nada de ruim" (EALS, 36 anos).

A maioria das mães freqüentava o dentista. Poucas disseram que não o faziam.

"Costumo. Eu vou de três em três meses. Ai!! Eu tenho que cuidá dos meus dente, né, é o meu dever também, porque tem que cuidá da boca, né? É importante, é saúde também, importante" (ALSS, 24 anos).

Apesar de a maioria dizer que freqüentava o dentista, verificou-se que metade das mães nunca tinha levado o filho ao consultório odontológico: "Não!! No dentista nunca levei não. Porque eles cuida na escola" (MLS, 40 anos).

As mães que disseram ter levado seu filho ou filha ao dentista, mesmo tendo em mente que naquele local eles sentiriam dor, associaram este ato: a) ao cuidado com os dentes, proporcionando ausência de cárie e conseqüentemente, dentes bonitos; b) à concepção de "ir ao dentista" como sinônimo de saúde para seu filho(a); e, c) ao direito do filho a esse benefício e ao dever de mãe de levá-lo ao dentista.

"Ah!! Eu acho, não acho nada, acho bom assim, né, que é levar para uma coisa boa, né? Às vezes, eu fico com pena, assim, que às vezes ela chora, né, a mais maior, chora, e já a pequena já não chora. Aí eu fico com medo porque dói, tem vez que pra limpar dói, né, aquela hora que eles pegam assim, dói, também aí. Pelas primeira vez ela chorava, mas depois eu conversei com ela que é pra limpar pra não ter bichinho, pra os dente ficar bonito, aí ela entende, né" (JJO, 27 anos).

Quando questionadas se, tendo a oportunidade, estariam dispostas a ir (naquele momento) ao consultório odontológico, para a realização de um tratamento, a maioria disse que sim.

"Ah! Eu iria. Ah! Porque eu gostaria de melhorar, né, meus dente" (ALSS, 24 anos).

"Sim. Ah! Sempre que marca, né, assim de... é, no começo assim eu ia todo mês. Agora não. Agora de 6 em 6, né, que tá... Sinto diferença (risos). É uma diferença, né, porque eles limpam muito bem, né, então você sente uma diferença. Não sinto medo" (ESA, 25 anos).

Não poder sair do trabalho e ter medo foram justificativas para não procurar assistência odontológica.

"Ah! Era bom, né, mas só que agora, nesse momento mesmo eu não posso. Porque eu tô trabalhando. Eu tô ali, ó, onde você me chamou. Eu não teria medo de ir" (MLS, 40 anos).

"Agora, agora eu não ia não! (risos) Porque agora não. Ai! Porque eu tenho medo! (risos)" (FCMC, 20 anos).

"Costumo. Eu vou de três em três meses. Ai! Eu tenho que cuidá dos meus dente, né, é o meu dever também, porque tem que cuidá da boca, né? É importante, é saúde também, importante. Ai!! O coração acelera (risos, desencostou do sofá). $O$ coração acelera um pouco (risos). Mas, tipo assim, eu não tenho muito medo, sabe? E quando eu sento, deito lá, eu fico assim um pouco tremendo (risos). Depois logo passa!!” (ALSS, 24 anos).

Os relatos evidenciam uma associação entre ter medo e não freqüentar o dentista, e entre 
não ter medo e freqüentá-lo, indicando que o medo pode estar sendo um obstáculo relevante à decisão de ir ou não ao dentista. Para Cruz et al. ${ }^{25} \mathrm{e}$ Singh et al. ${ }^{26}$ os procedimentos invasivos, como a anestesia e o aparelho de alta/baixa rotação ("motorzinho") seriam os que mais produzem medo nos pacientes submetidos ao tratamento odontológico.

Quando o ruído do aparelho de alta rotação, gravado numa fita cassete, foi reproduzido para as mães, para avaliar suas reações a esse estímulo característico, constatou-se que a maioria foi capaz de identificá-lo, associando-o com alguns sentimentos ruins como dor, arrepio, pânico e pavor.

"Ai! Tenho pavor desse barulhinho (desencostou do sofá). Olha!! Esse barulhinho, eu tenho pavor dele. Porque, nossa!!!, ele dói muito. E também ela também tem medo disso, desse barulhinho. Eu acho que quase todo mundo tem medo desse barulho, né?" (ALSS, 24 anos).

Apenas uma mãe disse não se lembrar de nada quando escutava o ruído característico, diferenciação esta justificada pelo fato de nunca ter ido ao dentista. Sem a vivência anterior desagradável, não se processava a associação ruído-medo.

A imagem de um dentista realizando o tratamento odontológico num paciente foi apresentada às mães, verificando-se que a metade achava a imagem normal. "Ah!! Nada. Normal. Vê mexendo na boca da gente? Normal" (ARL, 20 anos).

Uma mencionou ser ruim, horrível e a mãe que nunca tinha ido ao dentista disse que nada lhe vinha à cabeça.

A associação da figura do cirurgião-dentista e do tratamento odontológico à dor apareceu nos relatos de forma consistente. A dor veio associada a estímulos específicos de forma marcante, em relação, principalmente, ao tratamento e ao dentista de forma geral. A associação da dor a estímulos específicos, quando ocorre, envolve instrumentos e traduz, de certa forma, situações de agressão ao organismo do paciente, como o uso da broca/motor e agulha/anestesia. Em algumas entrevistas, a dor aparece como um fator desencadeador do medo.

Segundo Schuman et al. ${ }^{27}$, a prática odontológica é agressiva aos pacientes em quase todos os níveis sensoriais, incluindo audição, visão, olfação, tato e gustação. Nesta pesquisa, ao se analisar as situações desencadeantes de medo, verifica-se um predomínio da audição e do tato promovendo tais sensações. Chamou a atenção, especialmente, o fato de uma das entrevistadas, após demonstrar ter medo do aparelho de alta rotação, mencionar que o problema maior não era o barulho e sim o cheiro do consultório.

"Porque nem o barulho, nem nada, mas é o cheiro. O cheiro que faz... o cheiro que entra... uhm... Não, porque machucar não machuca, né, porque... mais é o cheiro, é, o cheiro do consultório" (CCC, 32 anos).

Outro fator que pode estar exercendo influência relevante na decisão de ir ou não ao dentista é a desigualdade no acesso e na utilização dos serviços odontológicos.

Apesar disso, segundo as entrevistadas, é muito mais fácil ir ao dentista, hoje em dia, do que no passado.

“Ah! Está! Antigamente, quase não existiria. Nossa! Era muito difícil. Olha! Quando a gente... Eu lembro que minha mãe arrancava tudo os dente. Antigamente, só arrancava, né, não cuidava dos dentes. Hoje tem um monte de coisa pra fazer no dente, pra recuperar o dente. E, assim, pra arrancar é só se não tiver jeito mesmo. E se você quiser também arrancar, né? Agora, eu arranquei, dois aqui do lado. Eu achava que não tinha mais jeito" (ALSS, 24 anos).

Esta maior facilidade decorre, segundo as mães, do aumento do número de unidades básicas de saúde (UBS), com a presença do dentista.

“Ah! Tá! Ah! Porque hoje onde você vai tem dentista. Todos os posto de saúde tem dentista. Ahn!! Você anda na cidade o que mais vê 
é consultório, né? Eu pelo menos, o que minha mãe fala, o meu pai fala, é que não tinha, era muito difícil. Que nem, meu pai mesmo fala que ele morava em Rifaina, só tinha dentista em Franca. Era difícil, né? Então, eu acho que hoje é mais fácil, apesar que hoje tudo é mais fácil, né, do que antigamente" (ESA, 25 anos).

Haveria aumento, também, segundo as mães, na quantidade dos materiais odontológicos, no desenvolvimento da área, e numa maior facilidade para marcar consultas. É provável que tal percepção seja conseqüência da presença e atuação, no território onde residem as mães participantes da investigação, do Núcleo de Saúde da Família IV, correspondendo esta visão positiva aos efeitos que a estratégia Saúde da Família proporciona. Não obstante, conforme referido, esses avanços ainda não lograram acabar com algumas dificuldades relacionadas com a demora para ser atendida e com o alto custo de alguns procedimentos odontológicos não cobertos pelos serviços públicos de saúde.

O serviço público de saúde aparece, geralmente, associado à demora e à falta de equipamentos/materiais, e o particular com a rapidez no atendimento e com a pontualidade. Neste estudo, frente à possibilidade de escolher ir a um "dentista do posto de saúde" ou a um "dentista particular", as entrevistadas não manifestaram, claramente, uma preferência. Algumas, porém, mencionaram que $\mathrm{o}$ atendimento particular seria mais rápido, sendo o paciente atendido com hora marcada e da maneira desejada. Observa-se, contudo, uma certa idealização do serviço particular. A opinião não decorre de uma experiência concreta nesses serviços, mas do senso comum socialmente reproduzido.

"Eu acho que o particular, né. Ai, não sei, eu vejo o povo falar muito bem do particular, né. E o do posto, assim, eu tenho medo, acho porque eu já fui várias vezes, eles não me atende do jeito que eu queria que eles atendesse. Aí eu acho que no particular acho que... eu acho que era melhor, né, não sei. Porque eu também nunca fui e nem posso, né" (risos) (FCMC, 20 anos).
Outras disseram que iriam ao dentista da UBS, pois foram bem tratadas. Esta percepção põe em relevo um aspecto ao qual se vem atribuindo crescente importância, tanto em serviços públicos quanto particulares: a humanização da assistência.

"Uhm! Eu preferia o do posto. Porque eu acho que eles trata melhor, bem melhor. Não sei, porque eu tratei em muito postinho, paguei muito também, entendeu, mas eu preferia do postinho porque eles trata melhor a gente" (CCC, 32 anos).

Poucas disseram que não viam nenhuma diferença e que iriam a qualquer um.

"Ah! Eu acho que pra mim é a mesma coisa. Pra mim é a mesma coisa. Ah!! É bom o particular porque você tá pagando e..., mas é o mesmo dentista que tá pagando, o dentista do posto faz a mesma coisa. Está fazendo a mesma coisa. Pra esse negócio, questão de demorar, também, o pago tá demorando a mesma coisa, então.., pra mim. Só que, é... particular é assim, se marcar você vai, né? $O$ posto demora um pouquinho, mas por mim não tem diferença" (ALSS, 24 anos).

Uma mãe disse que iria ao mais competente, independentemente se fosse da UBS ou particular:

“... Porque é difícil, porque você paga um convênio, às vezes o dentista não faz o que você quer, entendeu, e você vai no posto também não resolve, então fica difícil. Então, eu acho que vou no mais fácil, eu acho que no mais competente, né, pra fazer o serviço" (ESA, 25 anos).

Observa-se que pontualidade, qualidade, humanização, e competência são aspectos da assistência odontológica percebidos e valorizados pelas mães ouvidas neste estudo, e podem estar sendo cruciais na decisão de buscar ou não tais cuidados de saúde.

Cabe salientar, por fim, que essas repre- 
sentações sobre saúde bucal e cuidado odontológico, que emergiram nos discursos das mães, podem fazer parte e, portanto, expressar um pensamento maior. Ou seja: é possível admitir que outras mães, que apresentem características e condições de vida semelhantes, podem compartilhar desse pensamento.

O estudo aponta que a mãe atua como agente multiplicador de informações sobre saúde bucal, sendo crucial para a criação e manutenção do elo família-profissional.

Para além de se vincular essencialmente às ações assistenciais, o conceito de "saúde bucal" se restringe, na visão das mães ouvidas nesta pesquisa, à dimensão estética e pouco com as demais funções, provavelmente em conseqüência dos padrões predominantes numa sociedade que supervaloriza a aparência em detrimento de outros valores.

O papel do dentista nos cuidados à saúde bucal está relacionado às ações ditas "curativas", sendo as atividades preventivas pouco mencionadas, contradizendo a estratégia proposta pelo Programa de Saúde da Família. Isso, de certa forma, atende às expectativas das mães usuárias dessa unidade de saúde da família, que demonstram ter uma percepção muito fraca e difusa das atividades preventivas e associam a saúde bucal mais com a assistência curativa.

A associação do cuidado odontológico à dor, desencadeando o medo, resultado das experiências anteriores aversivas, levanta a necessi- dade de se conhecer a população a ser assistida para, dessa forma, orientar a prática do cirurgião-dentista.

Não obstante as desigualdades no acesso e na utilização dos serviços odontológicos, as mães acreditam estar mais fácil conseguir acesso ao dentista nos dias atuais, aparecendo como decisivos para a busca da assistência aspectos relacionados com a humanização e a competência do profissional.

Além disso, percebe-se, neste estudo, que o conhecimento das representações sociais dessas mães, pode contribuir para maior aproximação do serviço de saúde com os usuários, aumentando o vínculo equipe de saúde-população e, assim, adequar as estratégias de saúde voltadas à melhoria da qualidade de vida, ao melhor aproveitamento das capacidades adquiridas pelas pessoas, e, portanto, ao desenvolvimento humano.

Pode-se afirmar também que podem aumentar as possibilidades de êxito de estratégias programáticas em saúde pública, como as representadas pelo Programa de Saúde da Família, se em seu planejamento, implementação e avaliação, tais aspectos forem levados em conta, induzindo mudanças nas políticas de saúde, nas posturas acerca da concepção de saúde adotada pelos profissionais de saúde, além da melhor instrução da população, abrindo espaços à consideração dos valores e aspirações daqueles com os quais o programa se desenvolve.

\begin{abstract}
Objective: To investigate the social representations of mothers with children aged 0 to 5 years from the Family Health Nucleus IV, at the city of Ribeirão Preto, state of São Paulo, in order to know what they think about oral health and dental care. Methods: This is a qualitative study. Semi-structured interviews were employed to collect the data, which were submitted to content analysis. Results: The interviewed mothers showed an enormous difficulty to express what they think health is. For them, oral health is related to dietary and hygiene norms, and to going to the dentist. In addition, it is restricted to a concern for aesthetics, not for the function. Regarding dental treatment, it was verified that the great majority of the mothers are afraid of it, due to their previous experience with the treatment. Private dental treatment is associated with punctuality and with assistance provided in the desired way, and the treatment offered by the public sector, with delays and lack of equipment/materials. Two questions are important for them and they can be influencing the decision of going or not to the dentist: humanization and the professional's competence. Conclusions: The expression "oral health" was associated with dental assistance. The assistance provided by the private sector was characterized as the closest one to the ideal type of dental assistance.
\end{abstract}

Keywords: Representations; mothers; oral health; dental care. 


\section{REFERÊNCIAS}

1. Organização Mundial da Saúde. Carta de Ottawa.In: Ministério da Saúde/Fundação Oswaldo Cruz. Promoção da saúde: cartas de Ottawa, Adelaide, Sundsvall e Santa Fé de Bogotá. Brasília: Ministério da Saúde; 1986, p.11-8.

2. Canguilhem G. La santé: concept vulgaire et question philosophique. Toulouse, Sables, 1988; n.8, p. 118-33.

3. Coelho MTAD, Almeida Filho N. Conceitos de saúde em discursos contemporâneos de referência científica. História, Ciências, SaúdeManguinhos (Rio de Janeiro) 2002; 9(2): 315 - 33.

4. Brasil. Congresso Nacional. Lei n 8142, de 28 de dezembro de 1990. Dispõe sobre a participação da comunidade na gestão do sistema único de saúde e as transferências intergovernamentais de recursos financeiros na área da saúde. Publicado no D.O.U. em 31/12/90, 1990. [acesso em 11 de fevereiro de 2005]. Disponível em: http:/ /www.saude.rj.gov.br/legislacao_sus/.

5. Narvai PC. Definiçãa de saúde bucal. In: Saúde Bucal e incapacidade bucal. 2001. [acesso em 10 de julho de 2004]. Disponível em: http:// www.jornaldosite.com.br/arquivo/anteriores/ artcapel10anoIII .

6. Araujo MCM. Ortodontia para clínicos. Programa pré-ortodôntico. 4 ed., São Paulo: Livraria Editora Santos, 1988, 286 p.

7. Brasil. Ministério da Saúde. Secretaria de Atenção à Saúde. Departamento de Atenção Básica. Projeto SB Brasil 2003: condições de saúde bucal da população brasileira 2002-2003: resultados principais. Brasília: Ministério da Saúde, 2004. p. 14.

8. Queiroz MS. Estratégias de consumo em saúde entre famílias trabalhadoras. Cad. Saúde Pública (São Paulo) 1993; 9(3): 272-282.

9. Alves AR. Saúde e doença: uma abordagem sócio-cultural. In: Flores e Silva F. Saúde e doença: uma abordagem cultural da enfermagem. Florianópolis: Papa-Livro, 1996. Cap. 3, p. 56-74.

10. Bardin L. Análise de conteúdo. $7^{\text {a }}$ ed. Portugal (PT): Edições; 1977. 226 p.

11. Minayo MCS. O desafio do conhecimento. Pesquisa qualitativa em saúde. Rio de Janeiro: Hucitec-Abrasco, 1993, 269 p.

12. Karsch UMS. (Org). Envelhecimento com dependência: revelando cuidadores. São Paulo: EDUC, 1998, p. 47-85.

13. Morais H. Representação sobre o cuidado e a qualidade de vida do cuidador de idosos dependentes no Programa de Saúde da Família de Uberaba - MG. 2004. Dissertação (Mestrado). Faculdade de Medicina de Ribeirão Preto, Universidade de São Paulo. 2004.

14. Dias ELR, Wanderley JS, Mendes RT. (orgs) Orientações para cuidadores informais na assistência domiciliar. Campinas, SP: Editora da Unicamp, 2002, p. 11-16.

15. Carneiro AMO. Percepções em saúde bucal: valores, atitudes e problemas de um grupo de pessoas residentes na área rural de Brazilândia DF. 2001. Dissertação (mestrado) Faculdade de Odontologia, Universidade Federal de Minas Gerais, Belo Horizonte, 2001.

16. Fernandes MLMF. Análise comparativa das percepções em saúde bucal de adolescentes grávidas e não grávidas: um ponto de partida para a promoção em saúde bucal. 2002. Dissertação (Mestrado) Faculdade de Odontologia, Universidade Federal de Minas Gerais, Belo Horizonte, 2002.

17. Milgrom P. Response to Reisine \& Douglas: psychosocial and behavioral issues in early childhood caries. Community Dent Oral Epidemiology (Copenhagen) 1998; 26: 45-46.

18. Ferreira ARC, Gaiva MAM. Atenção odontológica para bebês: percepção de um grupo de mães. J. Bras. Ped.(Curitiba) 2001; 4(22): 485-489.

19. Lascala NT. Prevenção na clínica odontológica: promoção de saúde bucal. São Paulo: Editora Santos: São Paulo, 1997, 292 p.

20. Capra F. O ponto de mutação. A ciência, a sociedade e a cultura emergente. $10^{\mathrm{a}}$ Ed. São Paulo: Cultrix, 1990, 447 p.

21. Mendonça TC. Mutilação dentária: concepções de trabalhadores sobre a responsabilidade pela perda dentária. Cadernos de Saúde Pública 2001; 17(6): 1545-47.

22. Watt RG. Emerging theories into the social determinants of health: implications for oral health promotion. Community Dentistry and Oral Epidemiology (Copenhagen) 2002; 30(4): 241-247.

23. Milgrom P, Weinstein P, Getz T. Treating fearful dental patients. 2 ed., Washington: University of Washington in Seattle, 1995, p. 19-20.

24. Milgrom P, Fiset L, Melnick S. The prevalence and practice management consequences of dental fear in a major US city. J. Am. Dent .Assoc., 1988; 116: 641-647.

25. Cruz JS, Cota LOM, Paixão HH, Pordeus IA. A imagem do cirurgião-dentista: um estudo de representação social. Rev. Odontol. Univ.(São 
Paulo) 1997; 11(4): 307-313.

26. Singh KA, Moraes ABA, Ambrosano GMB. Medo, ansiedade e controle relacionados ao tratamento odontológico. Pesq. Odont. Bras. (São Paulo) 2000;14(2): 131-136.

27. Schuman NJ. Dentistry as portrayed in motion pictures on television. Compend. Contin. Educ. Dent., 1993; 14(1):102-106.

28. Matos DL, Lima-Costa MF, Guerra HL, Marcenes W. Projeto Bambuí: avaliação de serviços odontológicos privados, públicos e de sindicato. Rev. Saúde Púb. (São Paulo) 2002; 36(2): 237-243.

Recebido em: 09/11/2007

Modificado em: 11/02/2008

Aprovado em: 26/02/2008 